\title{
Increasing violence in Australian general practice is a public health issue
}

\author{
Leanne Rowe and Michael R Kidd
}

T he murder of Dr Khulod Maarouf-Hassan in her general practice in June 2006 (Box 1) has challenged the medical profession to consider the problem of violence in general practice. Debate has centred on protecting individual doctors with strategies such as secure physical practice environments, alarm systems, more intervention orders, and self-defence courses. Although such strategies are important, a systematic examination of the causes of increasing violence in general practice and the wider community is also needed, to identify a more effective longterm response.

Dr Maarouf-Hassan's death is a sentinel event in the rise of violence both against general practitioners and within the wider community. The main Australian study on the prevalence of violence in general practice reported that $63 \%$ of GPs experienced some form of violence in the previous year. ${ }^{1}$ Most affected GPs were women or doctors working in lower socioeconomic areas ${ }^{1}$ and rural areas. ${ }^{2}$ There is some evidence from the United Kingdom $^{3-5}$ and Australia 6 regarding the precipitants and causes of episodes of violence in general practice. The adverse effects on the health and work performance of GPs who experience violence have been documented, and include difficulty working in an enclosed space in subsequent consultations. ${ }^{\top}$

Although there are many gaps in our understanding, what can be observed is the significant increase in reports of assault in Australia over the past decade. ${ }^{8}$ There is congruence between increasing community violence and a perception of an increase in violence against GPs. ${ }^{3-6,9}$

Unfortunately, it is difficult to draw conclusions from national data on levels of reported assault because of differences in coding in each state and high levels of under-reporting. ${ }^{8}$ With these limitations aside, 184671 physical and sexual assaults were reported to police in Australia in 2005. ${ }^{10}$ These figures contrast sharply with the National Personal Safety Survey in 2005, which reported the results of personal interviews on experiences of

\section{The death of Dr Khulod Maarouf-Hassan}

On Friday 16 June 2006, 51-year-old general practitioner Dr Khulod Maarouf-Hassan was stabbed to death in her consulting room at her general practice in the south-eastern suburbs of Melbourne. The impact on her family, her colleagues and her patients has been deep and moving.

Khulod was born in Syria, graduated in medicine in 1978, and trained as an ophthalmologist. In 1986, she migrated to Australia with her family. She retrained as a GP and was awarded the Fellowship of the Royal Australian College of General Practitioners (RACGP) at the end of 2005.

Khulod was passionate about assisting refugees in her general practice. On the night before her death, she contributed to a professional development event on refugee health.

The Australian Medical Association and the RACGP have established "The Dr Khulod Maarouf-Hassan fund" to support Khulod's husband, Ayman Hassan, and their three children.

\section{ABSTRACT}

- Violence is a serious public health issue and the medical profession has a role to play in tackling this issue.

- Occupational violence is a significant problem in Australian general practice.

- Doctors need training to recognise and manage patients at risk of becoming perpetrators or victims of violent behaviour, both to protect themselves and to reduce violence in the wider community.

- A national taskforce on violence in medical practice should be established to monitor, evaluate, prevent, and reduce medical workplace violence.

- A national summit of all medical groups should be held to examine the increasing violence in Australian society as a public health issue.

- Australia's medical practitioners are in a strong position to advocate for better mental health, drug and alcohol, and family support services to manage patients at risk of violent behaviour.

MJA 2007; 187: 118-119

physical and sexual assault in a large representative sample of the population over 18 years of age and calculated that there were 808300 assaults on men and 443800 assaults on women in Australia in 2005. ${ }^{11}$

Increased awareness of family violence is responsible in part for the recent rise in reports of assault. ${ }^{10}$ In response, the Office for Women has worked to raise awareness in the community about the damaging effects of family violence in a campaign called "Australia says 'no' to violence against women". 12 However, much of the increase in assault appears to be related to violence against men by persons unknown. Increasing drug and alcohol use have also been implicated in the rise in violence. ${ }^{13}$

Mental illness associated with occupational violence in general practice has received little attention for a number of reasons. It is important to emphasise that most people who are violent are not mentally ill and most people who are mentally ill do not display violent behaviour. ${ }^{14}$ In fact, people with mental illness are more likely to be victims rather than perpetrators of violence. ${ }^{14}$ The long-term mental health effects of violence are well known, including post-traumatic stress disorder, anxiety, depression, suicide, and drug and alcohol misuse. ${ }^{7}$

There is a subgroup of people with serious mental illness and multiple risk factors who are at increased risk of being the perpetrators of violent behaviour. ${ }^{15}$ young men with active delusional psychosis, persecutory symptoms and disorganised thinking, who may be using substances, lacking insight, resistant to engagement, non-compliant with treatment and socially disadvantaged. These people should be recognised and managed assertively with inten- 


\section{Recommendations for action}

- A database of episodes of violence against general practitioners and their staff should be established to assist in monitoring, evaluating, preventing and reducing medical workplace violence.

- An Australian Government taskforce on violence in general practice should be established.

- A national summit of all medical groups should be held to examine the increasing violence in Australian society as a public health issue.

- GPs need training to recognise and manage patients at risk of becoming perpetrators or victims of violent behaviour, both to protect themselves and to reduce violence in the wider community.

- Advocacy is needed for increased support for services that can prevent children and adults at risk from becoming perpetrators or victims of violence.

sive, biopsychosocial intervention by a multidisciplinary mental health team. It is a paradox that such people are also at increased risk of being rejected by mental health and drug and alcohol services. In an environment of increasing burden of mental illness and substance use, coupled with medical workforce shortages and inadequate funding of mental health and drug and alcohol services, this is the group of people most likely to fall through the gaps of the health care system and end up in the criminal justice system. ${ }^{16}$

Violence in Australia is a major public health issue, and GPs have a role to play in seeking to prevent and deal with the complexities of violence. ${ }^{17,18}$ What is required is better training of all health professionals in recognising and managing people at risk of becoming perpetrators or victims of violence, and stronger advocacy for improved funding of state health services, including mental health services, drug and alcohol services, and family support services, particularly for disadvantaged groups.

Increasing violence in the community is a sign of disturbance in the social fabric of Australia. Violence against GPs and other health professionals should be considered in this wider context. To the Australian public, the death of Dr Maarouf-Hassan is another meaningless homicide statistic. To the medical profession, the tragedy of her loss should become a catalyst to begin a deeper public conversation about increasing violence and its long-term health effects on our individual patients and our communities. If GPs are to prevent another death of one of our own, doctors must do more than just protect themselves and inadvertently risk reducing access to health care for high-risk patients (Box 2).

In Victoria, the government has systematically addressed violence against nurses with a major taskforce, ${ }^{19}$ which has established mechanisms to promote consistent reporting and measurement of assault against nurses, and monitor, evaluate, prevent and reduce workplace violence. The Australian Government should develop a similar approach by establishing a national taskforce on violence in general practice to overcome current gaps in data and to promote a systematic approach.

A national summit of all medical groups on the expanding cycle of increasing violence in Australian society as a public health issue is recommended to address medical workplace violence in the context of increasing violence in the community.

What is needed most is a groundswell of concern by Australia's GPs for children and adults at risk of becoming perpetrators or victims of violence, millions of whom visit GP consulting rooms around our country every year.

\section{Competing interests}

None identified.

\section{Author details}

Leanne Rowe, AM, MB BS, MD, FRACGP, Adjunct Associate Professor, ${ }^{1}$ Deputy Chancellor ${ }^{2}$

Michael R Kidd, MB BS, MD, FRACGP, Professor and Head, ${ }^{1}$ Immediate Past President ${ }^{3}$

1 Discipline of General Practice, University of Sydney, Sydney, NSW.

2 Monash University, Melbourne, VIC.

3 Royal Australian College of General Practitioners, Melbourne, VIC.

Correspondence: michael@gp.med.usyd.edu.au

\section{References}

1 Magin PJ, Adams J, Sibbit DW, et al. Experiences of occupational violence in Australian urban general practice: a cross sectional study of GPs. Med J Aust 2005; 183: 352-356.

2 National Health and Medical Research Council. When it's right in front of you: assisting health care workers to manage the effects of violence in rural and remote Australia. Canberra: NHMRC, 2002. http:// www.nhmrc.gov.au/publications/synopses/hp16syn.htm (accessed Jun 2007).

3 Hobbs FD. Violence in general practice: a survey of general practitioners' views. BMJ 1991; 302: 329-332.

4 Ness GJ, House A, Ness AR. Aggression and violent behaviour in general practice: population based survey in the north of England. BMJ 2000; 320: 1447-1448.

5 Elston MA, Gabe J, Denney D, et al. Violence against doctors: a medical(ised) problem? The case of National Health Service general practitioners. Sociol Health Illness 2002; 24: 575-598.

6 Tolhurst H, Baker L, Murray G, et al. Rural general practitioner experience of work-related violence in Australia. Aust J Rural Health 2003; 11: 231-236.

7 Coles J, Koritsas S, Boyle M, Stanley J. GPs, violence and work performance. "Just part of the job". Aust Fam Physician 2007; 36: 189-191.

8 Australian Institute of Criminology. Crime and criminal justice statistics. Canberra: AIC, 2007. http://www.aic.gov.au/stats/ (accessed Jun 2007).

9 Health and Policy Economic Research Unit, British Medical Association. Violence at work: the experience of GPs in Northern Ireland. London: BMA, 2003. http://www.bma.org.uk/ap.nsf/AttachmentsByTitle/PDFviolenceNI/\$FILENiolenceNI.pdf (accessed Jun 2007).

10 Australian Bureau of Statistics. Recorded crime - victims, Australia, 2005. Canberra: ABS, 2006. (ABS Cat. No. 4510.0.)

11 Australian Bureau of Statistics. Personal Safety, Australia, 2005 (Reissue). Canberra: ABS, 2006. (ABS Cat. No. 4906.0.)

12 Office for Women. Violence against women, Australia says no [website]. Canberra: Office for Women, 2004. http://www.australiasaysno.gov.au (accessed Jun 2007).

13 Collins DJ, Lapsley HM. Counting the cost: estimates of the social costs of drug abuse in Australia in 1998-9. Canberra: Australian Government Department of Health and Ageing, 2000.

14 Friedman RA. Violence and mental illness - how strong is the link? N Engl J Med 2006; 355: 2064-2066.

15 Wallace C, Mullen PE, Burgess P. Criminal offending in schizophrenia over a 25-year period marked by deinstitutionalization and increasing prevalence of co-morbid substance use disorders. Am J Psychiatry 2004; 161: 716-727.

16 Mullen PE. Schizophrenia and violence: from correlations to preventive strategies. Adv Psychiatr Treat 2006; 12: 239-248.

17 Royal Australian College of General Practitioners. Safety for general practitioners and their practice teams: position statement of the Royal Australian College of General Practitioners. Melbourne: RACGP, 2007. http://www.racgp.org.au/gpissues/safety (accessed Jun 2007).

18 Mayhew C, Chappell D. Violence in the workplace. Med J Aust 2005; 183: 346-347.

19 Nurse Policy Branch, Victorian Government Department of Human Services. Victorian taskforce on violence in nursing. Final report. Melbourne: Nurse Policy Branch, 2005.

(Received 3 Apr 2007, accepted 29 May 2007) 